\title{
Validation of Simulation Model for Cogeneration Power and Water Desalination Plant
}

\author{
Mohammed A. Al-Weshahi, Alexander Anderson, Guohong Tian, and Basim M. A. Makhdoum
}

\begin{abstract}
Cogeneration power and MSF water desalination plant has been modelled using the IPSEpro software package based on plant operational scenarios and validated against measured recorded data from the plant. The relative differences between the model results and measured plant data vary from $1.1 \%$ to $3.7 \%$ for the power plant and $1.0 \%$ to $1.8 \%$ for MSF desalination. The model uncertainties could be attributed to either modelling assumptions or to input data uncertainties, with measured plant performance uncertainties due to measurement device precision and effects of external factors.
\end{abstract}

Index Terms-Cogeneration, modeling, IPSEpro, validation

\section{INTRODUCTION}

To analyze thermal systems (eg. cogeneration power and water desalination), computational modeling and simulation can avoid the restrictions and cost of physical testing [1]-[6]. However, model validation with measured plant operational data is then an important step before starting any analysis, either to justify the use of the model for further analyses or to demonstrate improvements to the model [7].

In arid and semi-arid countries power demand is characterized by high variation due to changes in the ambient temperature and relative humidity, whereas water demand remains almost the same over the whole year [8]. These changes result in operating cogeneration plant (power and water) in different seasonal scenarios to meet the variation in power while maintaining water supply. This causes significant variation in the plant performance parameters such as: net power and water production, thermal efficiency, heat utilization factor, and environmental impact (eg $\mathrm{CO}_{2}$ emissions). Thus, in assessing a simulation model it is essential to compare it with measured plant performance across the range of expected operational scenarios and ambient environmental conditions. This highlights the value of the validated plant model to provide operating engineers with a tool to understand performance indicator variation associated with changing the operating scenario and the possibility of operation optimization. Therefore, this study has three aims:

- To model a cogeneration plant (power and water) using the IPSEpro software package [9]-[10] for the purposes of investigating plant operations and improvements.

- To validate this model by comparison against measured

Manuscript received November 15, 2012; revised January 28, 2013

Mohammed A. Al-Weshahi, Alexander Anderson, and Guohong Tian are with Newcastle University, UK (e-mail: m.al-washahi@ncl.ac.uk, sandy.anderson@ncl.ac.uk, guohong.tian@ncl.ac.uk).

Basim M. Makhdoum is with Umm Al-Qura University, Saudia Arabia (e-mail: basim.makhdoum@ncl.ac.uk) plant data over a range of typical operating scenarios.

- To investigate the variations in performance when changing operating scenarios.

\section{Plant DESCRIPTION}

Fig. 1 describes the plant studied which has the specifications listed in Table I. The Gas Turbine (GT) exhaust is directed to the Heat Recovery Steam Generator (HRSG), which provides high-pressure steam to the High Pressure Turbine (HPT) [11] to provide further power. The major part of the steam moving to the Low Pressure Turbine (LPT) is extracted to the Multi Stage Flash (MSF) distiller. The pressure of the MSF desalination steam is maintained through a cross-over valve, which dumps excess LP steam to the LP turbine. MSF LP steam is used to heat the seawater in the MSF brine heater and then returns back to the power plant deaerator after mixing with condensate that comes from the LP steam turbine condenser. To maintain water production in case of lower power demand when the GT load is reduced which causes less production of steam from the HRSG, Supplementary Firing (SF) for both boilers is used to maintain steam production to the desalination units through the steam turbine.

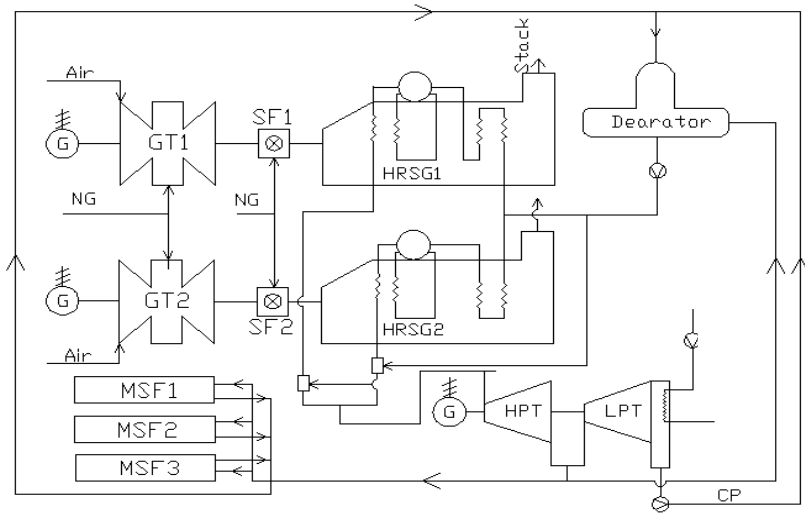

Fig. 1. Schematic of the combined power and desalination plant

Fig. 2 describes the MSF evaporator. The main sea water pump (SWP) supplies the seawater to heat rejection stages 19, 18 and 17. Most of this of this seawater will be rejected again to the sea while part of it will pass to the deaerator as makeup. Inside the deaerator, oxygen is removed from the sea water to avoid tube corrosion of the heat recovery stages 1 to 16. Recycle brine (which is the sea water that is accumulated in the deaerator or last stage) is transferred by brine recycle pump (BRP) to the tube side of the heat recovery stages, where the flashed brine at the condenser of each stage gradually heats it. After exiting from stage 1 the brine is finally heated to its terminal temperature by the heating steam in the brine heater. It then flows to stage 1 of 
the evaporator where the initial flash evaporation occurs. As the brine would be still hot enough to boil again at slightly lower pressure, the flashing process is then repeated as it passes through a series of interconnected stage chambers. Flashed vapor is condensed by the cooling water in the tubes, then condensed distillate flows from each stage to a common distillate channel and extracted finally by the distillate pump (DP).

TABLE I: PLANT COMPONENT CHARACTERSTICS

\begin{tabular}{|c|c|}
\hline Unit & Characteristics \\
\hline GT & $\begin{array}{l}\text { Characteristics at } 15^{\circ} \mathrm{C} \& 60 \% \text { Relative Humidity } \\
-\quad \text { Power generation: } 158 \mathrm{MW} \\
-\quad \text { Exhaust mass flow rate: } 519 \mathrm{~kg} / \mathrm{s} \\
-\quad \text { Turbine Exhaust temperature: } 539^{\circ} \mathrm{C} \\
-\quad \text { Thermal Efficiency: } 34.5 \% \\
-\quad \text { Lower heating value: } 44000 \mathrm{~kJ} / \mathrm{kg}\end{array}$ \\
\hline HRSG & $\begin{array}{lc}\text { Characteristics at } 50^{\circ} \mathrm{C} \& 100 \% \text { Relative Humidity } \\
-\quad \text { Steam production without firing: } 248 \mathrm{t} / \mathrm{h} \\
-\quad \text { Steam production with firing: } 436 \mathrm{t} / \mathrm{h} \\
\end{array}$ \\
\hline ST & $\begin{array}{ll}- & \text { Power generation: 222MW } \\
- & \text { Mechanical efficiency: } 87 \% \\
- & \text { HP turbine outlet pressure: } 1.50 \mathrm{bar} \\
- & \text { LP turbine maximum flow is: } 392 \mathrm{t} / \mathrm{h} \\
- & \text { LP turbine maximum flow: } 50 \mathrm{t} / \mathrm{h} \\
- & \text { Condenser pressure: } 0.100 \mathrm{bar}\end{array}$ \\
\hline MSF & \begin{tabular}{ll}
\multicolumn{2}{l}{ Characteristics at $35^{\circ} \mathrm{C}$ seawater temperature \& full load } \\
$-\quad$ Production: $3800 \mathrm{~m}^{3} / \mathrm{h}(3$ units) \\
$-\quad$ Stages: 16 Heat Recovery +3 Heat Rejection \\
$-\quad$ Performance ratio: 8.40 \\
$-\quad$ Top brine temperature: $105^{\circ} \mathrm{C}$ \\
$-\quad$ Recirculation flow: $12900 \mathrm{~m}^{3} / \mathrm{h}$
\end{tabular} \\
\hline
\end{tabular}

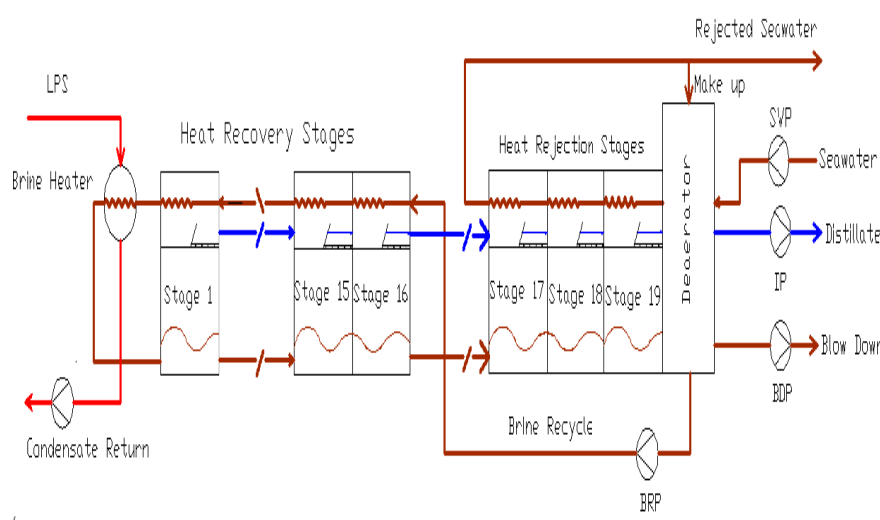

Fig. 2. Schematic of the MSF distiller

\section{Plant OpERATION SCENARIOS}

Measured data were collected for a history of system data retrieved every hour over a year. Around 4209 filtered readings (excluding plant shutdowns, plant trips and instrumentation malfunctioning) were taken for Fig. 3, which shows a typical trend of water production and power generation for arid and semi-arid countries [12], [13].

From this, three typical operation scenarios were identified: Scenario 1: 2 GT +2 HRSG +1 ST + MSF (62\% of year), Scenario 2: $1 \mathrm{GT}+1 \mathrm{HRSG}+\mathrm{MSF}$ (32\% of year), and Scenario 3: $1 \mathrm{GT}+1 \mathrm{HRSG}+1 \mathrm{ST}+\mathrm{MSF}$ (8\% of year). Scenario 1 with all of the plant equipment in operation for power and water production is typical for arid zone countries where the ambient temperature in summer reaches a maximum of $42^{\circ} \mathrm{C}$ and does not reduce below $27^{\circ} \mathrm{C}$ [14].
Scenario 2 and Scenario 3 represent winter season time where the requirement for power is less (only a single gas turbine) and demand for water remains with minimum 2 MSF units in service. For Scenario 2, the steam turbine is shut down (lowest power demand) and LP steam for the MSF distillers is maintained with an HP/LP reduction station using an attemperator to adjust the LP steam temperature.

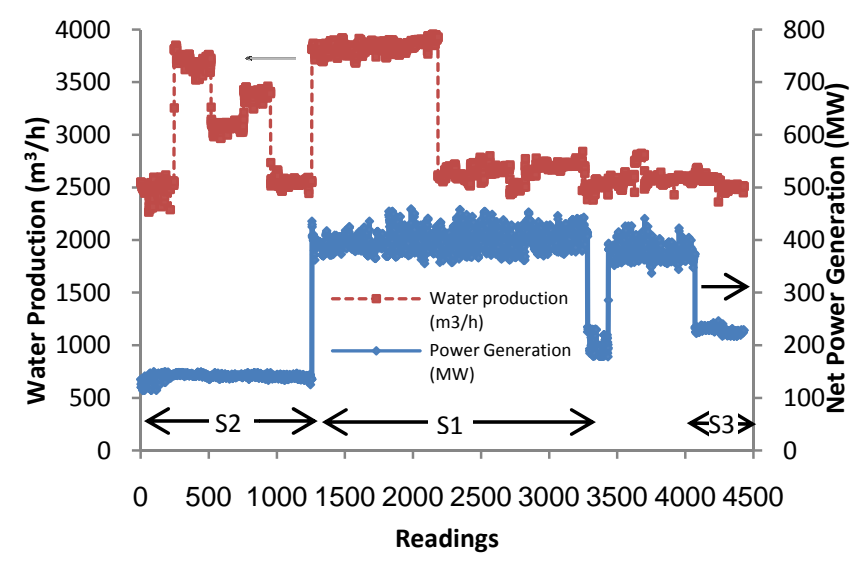

Fig. 3. Plant measured data historical power and water production

\section{Cogeneration Plant Modeling}

For validation, comparisons should take place between the same parameters as either inputs or outputs as well as environmental parameters (ambient humidity, ambient temperature and ambient pressure). The input and output parameters of the IPSEpro model [15], [16] have been based on the real plant control room operator interfering with the actual plant. Consequently, the model input variables for both power plant and MSF desalination unit were the same parameters that the control operator changes and the outputs were the results of the plant responding to these changes. For the power plant model, Table II describes the model inputs (extracted from the measured plant data) and the outputs (used for validation parameters between the measured data and model results). Similarly, Table III describes the inputs and outputs for the MSF desalination unit model.

\section{MODEL VALIDATION}

To ensure representative comparisons for these three scenarios to reflect the model confidence level, the data are sorted based on the ambient temperature and relative humidity. Three data sets were selected from each $1^{\circ} \mathrm{C}$ range, minimum, median and maximum. Total numbers of data sets used in this validation were $N=40,48$ and 32 readings for Scenarios 1, 2 and 3 respectively.

The model confidence level was assessed by the calculation of relative difference between measured $\left(X_{\mathrm{i}}\right)$ and model $\left(\mathrm{Y}_{\mathrm{i}}\right)$ data combined for each of the three scenarios [17]:

$$
e=\sqrt{\frac{\sum\left(e_{i}\right)^{2}}{N}} \text { where } \mathrm{e}_{\mathrm{i}}=\left[\frac{X_{i}-Y_{i}}{X_{i}}\right] \times 100(\%)
$$

Fig. 4 to Fig. 8 compares model results and measured data for the power plant. In contrast, validation of the MSF desalination model has had to be limited to comparison with vendor data (Fig. 9) due to the unavailabity of detailed plant 
operation measurement systems for the series of MSF stages [18]. For the MSF validation (Fig. 9) the relative differences were small (in the range $1.0 \%-1.8 \%$ ). The main source of these differences was the unavailability for modeling of the stage dimensions and detail design characteristics such as overall heat transfer coefficient and stage tube area.

TABLE II: POWER PLANT INPUT/OUTPUT PARAMETERS

\begin{tabular}{llll}
\hline Model inputs & \multicolumn{3}{c}{ Model outputs } \\
\hline \hline Ambient temperature & ${ }^{\circ} \mathrm{C}$ & GT gas flow & $\mathrm{kg} / \mathrm{s}$ \\
GT load & $\mathrm{MW}$ & HRSG steam flow & $\mathrm{t} / \mathrm{h}$ \\
Supplementary firing & $\mathrm{kg} / \mathrm{s}$ & ST load & $\mathrm{MW}$ \\
Steam pressure & $\mathrm{bar}$ & Condensate flow & $\mathrm{kg} / \mathrm{s}$ \\
Steam temperature & ${ }^{\circ} \mathrm{C}$ & MSF unit load & $\mathrm{kg} / \mathrm{s}$ \\
\hline
\end{tabular}

TABLE III: MSF UNIT INPUT/OUTPUT PARAMETERS

\begin{tabular}{llll}
\hline Model inputs & & Model outputs & \\
\hline Top brine temperature & ${ }^{\circ} \mathrm{C}$ & Steam flow & $\mathrm{t} / \mathrm{h}$ \\
Brine recirculation flow & $\mathrm{kg} / \mathrm{s}$ & Makeup flow & $\mathrm{kg} / \mathrm{s}$ \\
Seawater inlet temperature & ${ }^{\circ} \mathrm{C}$ & Blow down flow & $\mathrm{kg} / \mathrm{s}$ \\
Seawater feed flow & $\mathrm{kg} / \mathrm{s}$ & Stages brine temperature & ${ }^{\circ} \mathrm{C}$ \\
Distillate production & $\mathrm{kg} / \mathrm{s}$ & Stages distillate & ${ }^{\circ} \mathrm{C}$ \\
& & temperature & \\
& & Stages cooling water & ${ }^{\circ} \mathrm{C}$ \\
\hline
\end{tabular}

For the power plant validation, the model gas flow for all three scenarios is predicted closely with differences in the range $1.1 \%$ to $1.7 \%$ (Fig. 4). In Scenario 1 both GTs are used giving $2 \times 40$ readings (where Scenario 2 and 3 use only one GT). These differences in gas flow probably represent the best that can be expected from a simulation model taking into account the precision of the measurement devices. Both Scenario 1 data sets are correlated against ambient temperature in Fig. 4 and show greater differences at higher temperature. This suggests there may be issues with simulation model, e.g. assumption of constant Lower Heating Value (LHV).

The differences in HRSG steam flow measurements (Fig. 5) could be the result of data measurement uncertainty (from measurement devices precision and location, etc.) or model deficiencies or both. The model HRSG flow could be affected by other related model parameters (such as steam pressure, steam temperature or even calculated gas turbine exhaust mass flow rate and exhaust temperature) as well as external (unmodelled) factors. In Scenario 1 both HRSG are operational, giving $2 \times 40$ readings (whereas scenarios 2 and 3 use only one HRSG). One of the HRSG records steam flows higher than the other by almost $15-20 \mathrm{t} / \mathrm{h}$, when both of them are in principle identical and at the same operating conditions. With the readings sorted by ambient temperature, this difference was observed only at low ambient temperature and the difference reduces with increase of ambient temperature (Fig. 5). This indicates issues with site measured data, either due to instrumentation problems for one of the HRSG units, or due to features of the plant not modeled in the simulation. In turn, these latter could be due to either differences in the otherwise nominally identical plant physical layout not incorporated into the model, or issues such as unidentified (and thus unmodeled) flange leakage.

Steam turbine load validation took place only for two scenarios (Fig. 6), since it is shut down for Scenario 2.
Measurement device uncertainty is not likely to be significant for the steam turbine load, because these are payment dependent devices and have to be checked and certified for billing purposes. The differences between model results and measured data are $1.4 \%$ for Scenario 1 and $3.7 \%$ for Scenario 3 . The trend of the model data suggests that the higher Scenario 3 steam turbine load difference may be due to the assumption of constant mechanical efficiency in the model because the differences are almost the same for all comparisons.

Understanding the plant operation is important in analyzing the patterns for MSF flow and ST condensate flow (Fig. 7-8). Reduction of the MSF flow results in raising steam passing to the LP turbine and increasing ST condensate. This relationship can be observed by noticing the improvement for the Scenario 2 validation where there is no condensate flow.
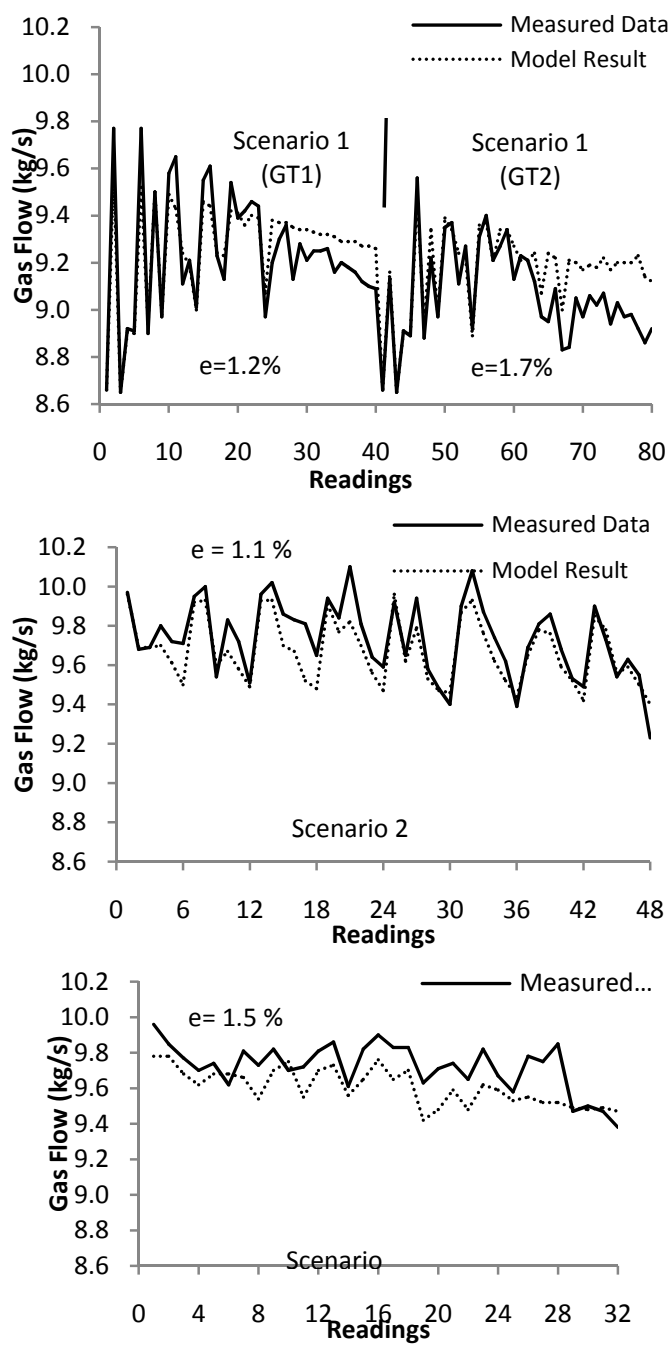

Fig. 4. Power plant validation: gas flow (kg/s)

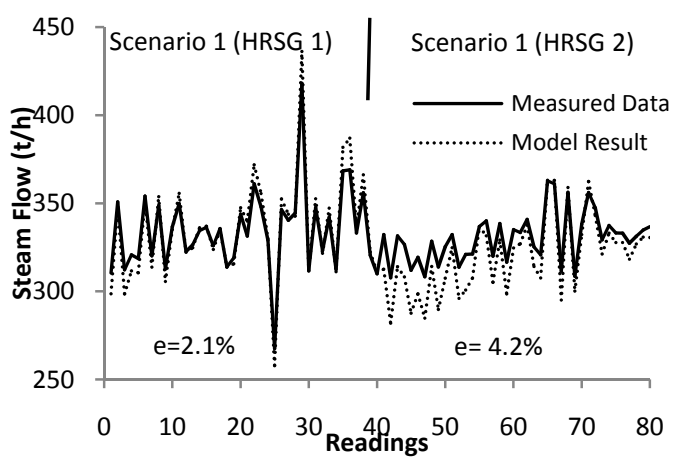



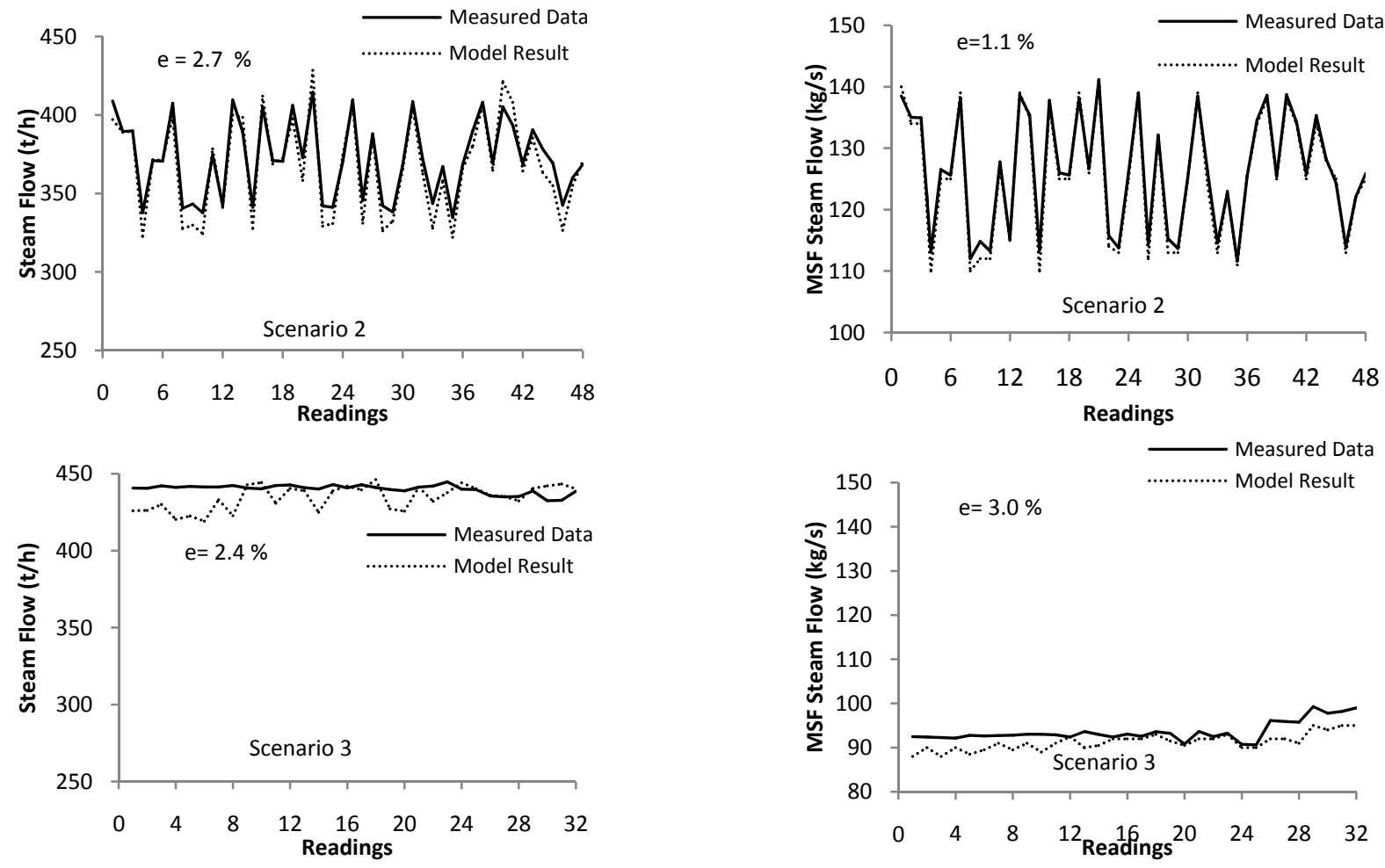

Fig. 5. Power plant validation: steam flow $(\mathrm{t} / \mathrm{h})$

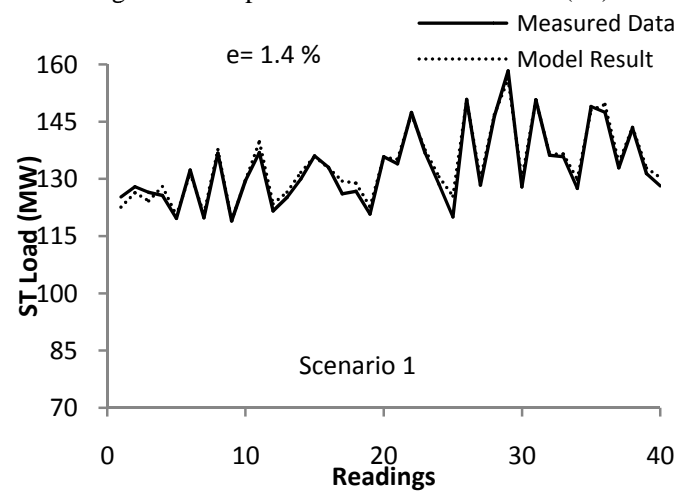

Fig. 7. Power plant validation: MSF flow (kg/s)
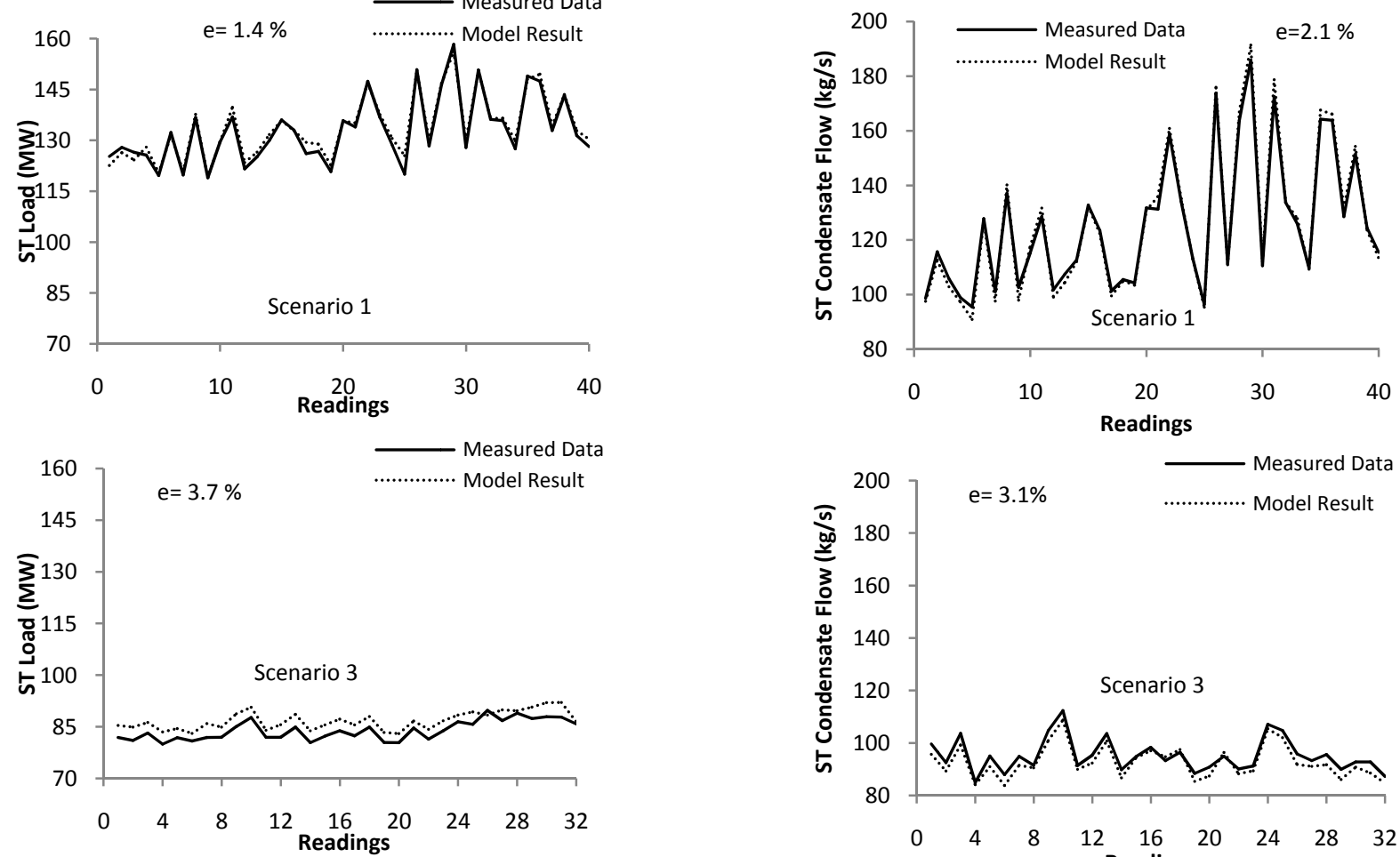

Fig. 6. Power plant validation: ST load (MW)
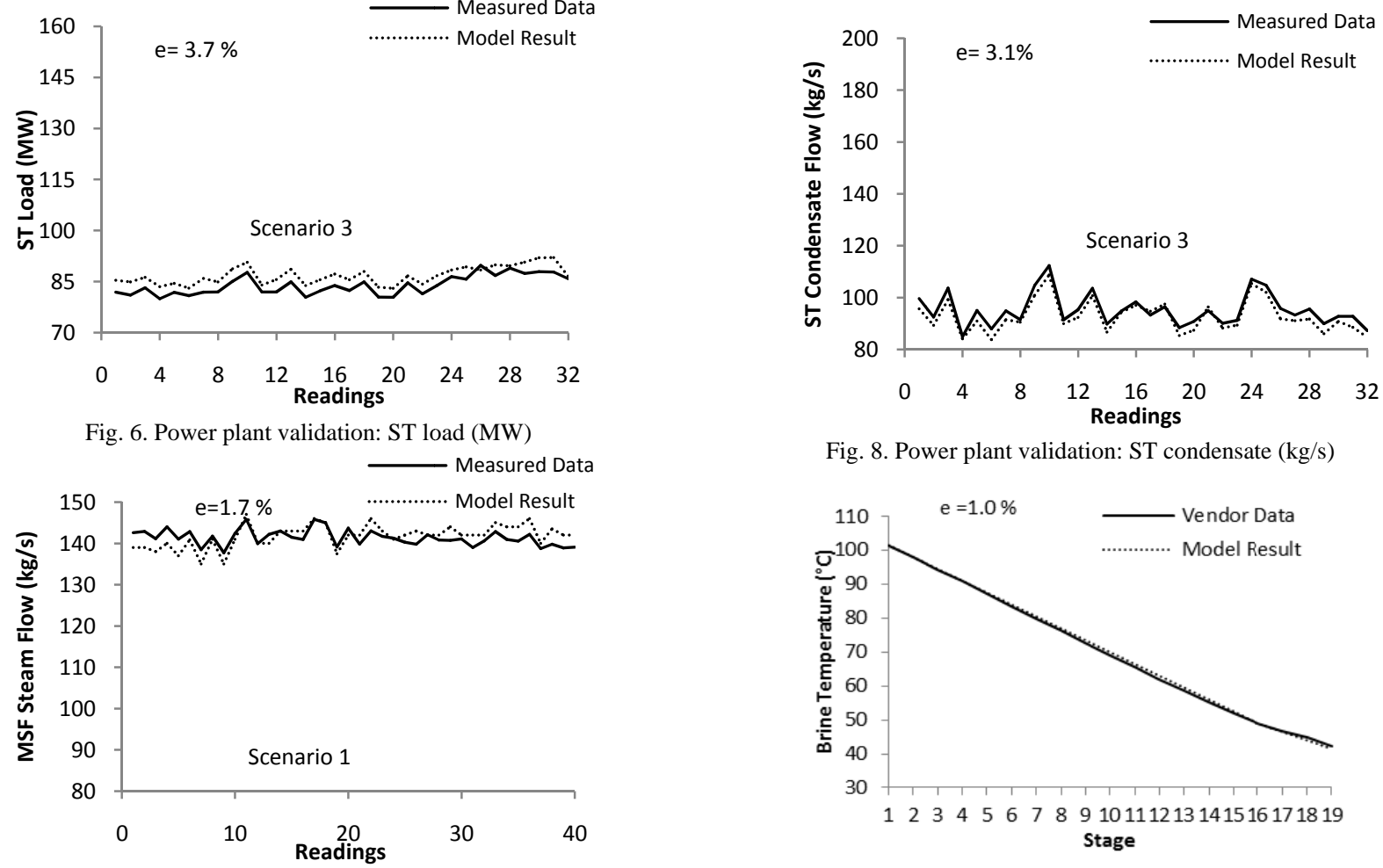

Fig. 8. Power plant validation: ST condensate (kg/s)

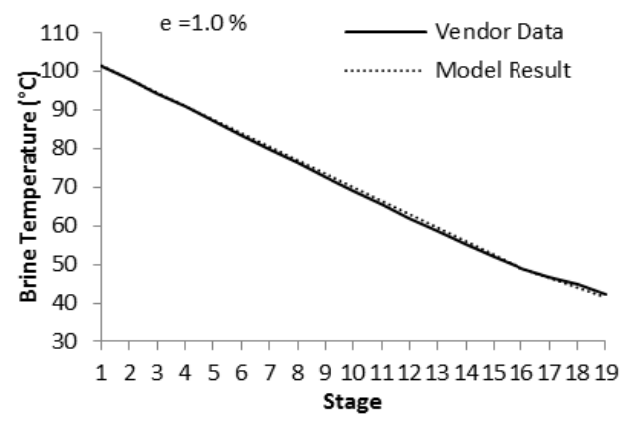



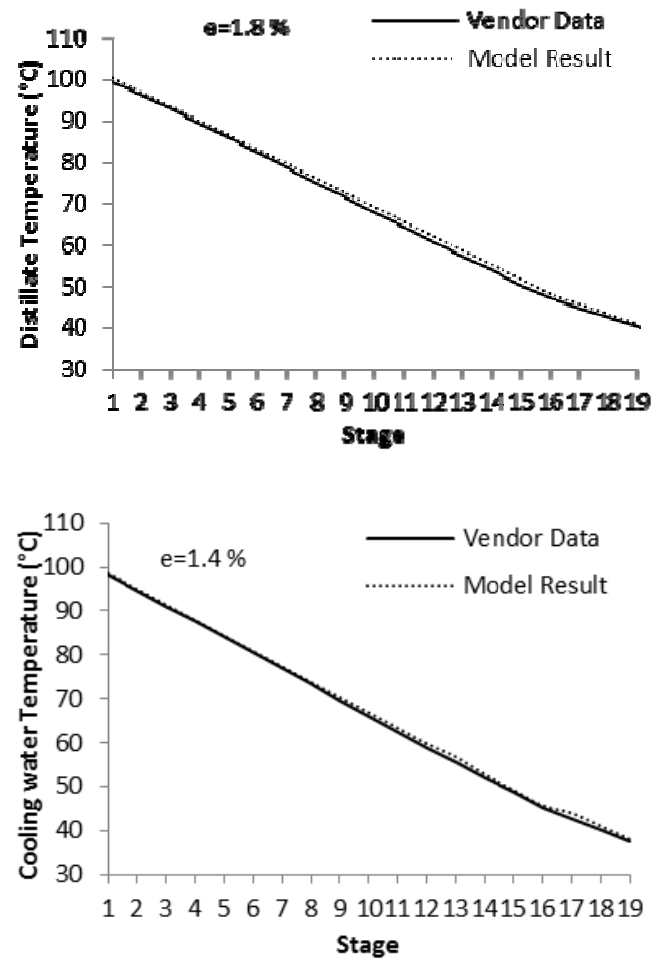

Fig. 9. MSF model validation through comparison with vendor data

\section{SCENARIO PERFORMANCE Assessment}

To adequately validate the simulation model it is important to recognize the implications of the range of normal operational scenarios. To illustrate the influence of the three scenarios on thermal capability then net power and water production, auxiliary power consumption, thermal efficiency and Heat Utilization Factor (HUF) can be considered. Plant net power is the sum of power produced by both GT and ST after subtracting the plant auxiliaries power consumption:

$$
\dot{W}_{\text {net }}=\dot{W}_{G T}+\dot{W}_{S T}-\dot{W}_{A u x}
$$

Using the total amount of Natural Gas (NG) consumed by the GT and SF:

$$
\dot{m}_{N G}=\dot{m}_{G T}+\dot{m}_{S F}
$$

Then overall power plant only thermal efficiency is obtained by [19]:

$$
\eta_{t h, P P}=\frac{\dot{W}_{n e t}}{\dot{m}_{N G} \times L H V}
$$

For cogeneration with water desalination (producing both power and potable water), Heat Utilization Factor (HUF) is [19]:

$$
\operatorname{HUF}(\%)=\frac{\dot{W}_{n e t}+\left[\dot{m}_{L P S} \times\left(h_{i}-h_{e}\right)\right]_{M S F}}{\dot{m}_{N G} \times L H V}
$$

To assess environmental impact of the three scenarios, $\mathrm{CO}_{2}$ emissions can be judged by[6], [19]:

$$
\mathrm{CO}_{2} \text { Emissions }\left(\frac{g}{k W h}\right)=\frac{\alpha \times \dot{m}_{N G}}{\dot{W}_{n e t}+\dot{Q}_{M S F}}
$$

where is $\alpha=3124 \mathrm{~kg} \mathrm{CO}$ per tonne of natural gas [20] and $\dot{Q}_{M S F}$ is absorbed heat by MSF desalination.

Table IV shows a comparison between the three representative operating scenarios taken at ISO condition (15 ${ }^{\circ} \mathrm{C}$ and $60 \%$ Relative Humidity).

TABLE IV: COMPARISON BETWEen THE THREE OPERATING SCENARIOS

\begin{tabular}{ccccc}
$\begin{array}{l}\text { Performance } \\
\text { Indicator }\end{array}$ & Unit & Scenario 1 & Scenario 2 & Scenario 3 \\
\hline \hline $\mathrm{W}_{\text {net }}$ & $\mathrm{MW}$ & 507 & 139 & 226 \\
$\eta_{\mathrm{PP}}$ & $\%$ & 43.3 & 23.4 & 37.9 \\
$\mathrm{HUF}$ & $\%$ & 68.5 & 76.4 & 84.6 \\
$\mathrm{CO}_{2}$ & $\mathrm{~g} / \mathrm{kWh}$ & 375 & 336 & 302 \\
\hline
\end{tabular}

Both power and water production are highest at Scenario 1 to meet the high power and water demand for the hot summer season. Consequently, plant auxiliary power consumption is higher at Scenario 1 compared to the other two, whereas Scenario 2 has the lowest auxiliary consumption due to the shut down of one of the gas turbines and the steam turbine with their auxiliaries. Scenario 1 power plant efficiency was higher than other scenarios due to higher power/natural gas ratio (more power from the amount of natural gas burned). However, utilization of the heat (MSF desalination taken into consideration) is more effective at Scenario 3, where steam flow from a single HRSG is used to run the steam turbine at lowest possible LPT steam flow. In contrast, the low heat utilization in Scenario 1 was mainly due to stack heat losses from both fired HRSG compared with only one HRSG in operation for Scenarios 2 and 3. As a consequence, the higher HUF at Scenario 3 explains the lower $\mathrm{CO}_{2}$ emissions compared with scenarios 1 and 2. To pursue these issues further, a detailed exergy analysis can be carried out using the validated model [21].

\section{CONCLUSION}

A model validation of a cogeneration plant has been presented. The selected model input and output parameters were based on the plant daily operation philosophy and model validation was carried out through comparisons of model outputs against the measured plant data or vendor data. To support validation appropriate across the range of plant operational duties, it has been demonstrated how an operation scenario performance assessment was carried out to investigate the impact of changing operating scenarios on the power and water cogeneration plant performance indicators.

The results suggest that the real tolerance on data supplied to the model (all themselves measured) plus the real performance measurement uncertainties restrict the achievement of the model predications to within about $1 \%$ of measured plant performance. In this study, though, the difference may be as high as 3.7\%, suggesting that further improvement remains possible. However, even at this level, it is reasonable to suggest that this model may be used for further investigation of this cogeneration plant.

The results show the differences between the model results and measured data varying from $1.1 \%$ to $3.7 \%$ for the power plant and $1.0 \%$ to $1.8 \%$ for MSF desalination. These differences result either due to various model assumptions or to measured data uncertainties. It has been demonstrated how 
the validation process can identify potential issues with site operation or instrumentation (e.g. HRSG steam flow), as well as highlighting the need for possible modeling enhancement (e.g. GT gas flow, ST load). Finally, one issue of validation against real plant is that plant operational instrumentation may not exist to enable all aspects of the model to be fully tested (e.g. MSF).

\section{REFERENCES}

[1] E. M. Ferreira, J. A. Balestieri, and M. A. Zanardi, "Optimization analysis of dual-purpose systems," Desalination, vol. 250, pp. 936-944, 2010.

[2] R. Borsani and S. Rebagliati, "Fundamentals and costing of MSF desalination plants and comparison with other technologies," Desalination, vol. 182, pp. 29-37, 2005.

[3] I. S. Al-Mutaz and A. M. Al-Namlah, "Characteristics of dual purpose MSF desalination plants,” Desalination, vol. 166, pp. 287-294, 2004

[4] M. A. Darwish, F. Al-Awadhi, A. Akbar, and A. Darwish, "Alternative primary energy for power-desalting plants in Kuwait: The nuclear option I," Desalination, vol. 1, pp. 25-41, 2009.

[5] M. A. Darwish, N. M. Al-Najem, and N. Lior, "Towards sustainable seawater desalting in the Gulf area,” Desalination, vol. 235, pp. 58-87, 2009.

[6] S. Masheiti, "A thermodynamic and economic simulation modelling study of utilizing low-temperature sources to power absorption and organic Rankine cycles,” Ph.D. dissertation, Dept. Mech. Eng., Newcastle Univ., Newcastle, UK, 2011.

[7] A. Anderson and A. Bergant, "Issues in 'benchmarking' fluid transients software models," in Proc. 10th International conference on pressure surges: surge analysis - system design, simulation, monitoring and control, BHR Group, Edinburgh, UK, 2008, pp. 519-537.

[8] M. A. Darwish and N. Al-Najem, "The water problem in Kuwait," Desalination, vol.177, pp.167-177, 2005.

[9] IPSEpro process simulator manuals: process simulation environment, SimTech Simulation Technology: Austria, 2005.

[10] IPSEpro process simulator manuals: Model Development Kit, SimTech Simulation Technology: Austria, 2005.

[11] M. Ameri, P. Ahmadi, and S. Khanmohammadi, "Exergy analysis of a 420MW combined cycle power plant,” Int. J. Energy Res., vol. 32, pp. 175-183, 2008.

[12] Oman Power and Water Procurement Company. Annual Report, OPWP: Oman, 2009.

[13] Oman Power and Water Procurement Company. OPWP's 7- Years' Statement (2010-2016), OPWP: Oman, 2010.

[14] A. A. Alsairafi. (July 2011). Effects of ambient conditions on the thermodynamic performance of hybrid nuclear-combined cycle power plant. Int. J. Energy Res. [Online]. Available: http://onlinelibrary.wiley.com/doi/10.1002/er.1901

[15] J. Rheinlander, E. W. Perz, and O. Goebel, "Performance simulation of integrated water and power systems - software tools IPSEpro and RESYSpro for technical, economic and ecological analysis," Desalination, vol. 173, pp. 57-64, 2003.

[16] M. Aneke, B. Agnew, and C. Underwood, "Performance analysis of the Chena binary geothermal power plant,” Appl. Therm. Eng., vol. 31, pp. 1825-1832, 2011.

[17] S. Dubey, and G. N. Tiwari, "Thermal modeling of a combined system of photovoltaic thermal (PV/T) solar water heater,” Solar Energy, vol. 82, pp. 602-612, 2008.

[18] S. A. Abdul-Wahab, K. V. Reddy, M. A. Al-Weshahi, S. Al-Hatmi, and Y. M. Tajeldain, "Development of a steady-state mathematical model for multistage flash (MSF) desalination plant,” Int. J. Energy Res., vol. 36, pp. 710-723, 2012.

[19] F. A. Al-Sulaiman, F. Hamdullahpur, and I. Dincer, "Performance comparison of three trigeneration using organic rankine cycles," Energy, vol. 36, pp. 5741-5754, 2011.

[20] K. Al-Zahrani, "Operation simulation and economical modelling study on utilizing waste heat energy in a desalination plant and an absorption chiller,” Ph.D. dissertation, Dept. Mech. Eng., Newcastle Univ., Newcastle, UK, 2010

[21] M. A. Al-Weshahi, A. Anderson, and G. Tian. (February 2012). Exergy efficiency enhancement of MSF desalination by heat recovery from hot distillate water stages. App. Therm. Eng. [Online]. Available: http://dx.doi.org/10.1016/j.applthermaleng.2012.02.013

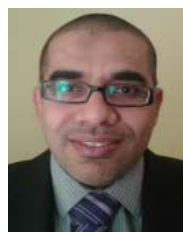

Mohammed A. Al-Weshahi is currently a Ph.D. student at Newcastle University, UK. He received his B.Eng. and M.Sc. (Eng) from Sultan Qaboos University, Oman. His research interests include thermal systems analysis and heat recovery technologies.

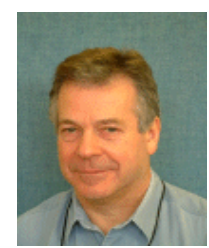

Alexander Anderson is currently a senior lecturer a Newcastle University, UK. He received his B.Sc. (Eng) and $\mathrm{PhD}$ from University of Aberdeen, UK. His research interests include fluid transients, CFD, robust design and thermal systems optimization.

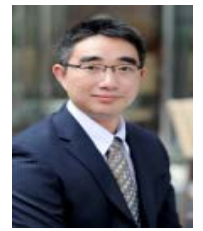

Guohong Tian is currently a lecturer at Sir Joseph Swan Centre for Energy Research, Newcastle University, UK. He received his B.Eng., MEng and Ph.D. from Tsinghua University, China. His research interests include renewable energy utilization and innovative engine technologies.

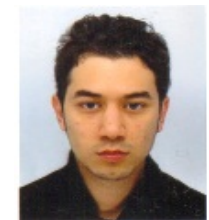

Basim M. A. Makhdoum is currently an assistant professor at Umm Al-Qura University, Saudia Arabia. He received his B.Sc. (Eng), from Umm Al-Qura University, Saudia Arabia and M.Sc., Ph.D. from Newcastle University. His research interests include thermal systems analysis and heat recovery technologies. 